\title{
Transistor Gating Technique: Designing of Full Subtractor Circuit Implementing Sleepy Transistors in $\mathbf{4 5}$ nm Technology
}

\author{
Tanvi Nagariya \\ (M.Tech student) \\ NRI Institute of Information \\ Science and Technology, \\ Bhopal, M.P, India
}

\author{
Braj Bihari Soni \\ (Assistant Professor) \\ NRI Institute of Information \\ Science and Technology, \\ Bhopal, M.P, India
}

\begin{abstract}
Full subtractor is a combinational circuit that performs subtraction between the three inputs and provides result in difference and borrow outputs. Implementing the MTCMOS technique on this circuit results in reduction of leakage current and power consumption. The proposed Full Subtractor has been designed and simulated using DSCH 3.1 and MICROWIND 3.1 software. The simulation technology used is $45 \mathrm{~nm}$. The simulation level is BSIM advanced level. The proposed design power consumption calculated as $0.341 \mathrm{~mW}$ and maximum current $\mathrm{I}_{\mathrm{dd}} \max$ equal to $2.420 \mathrm{~mA}$ at 0.7 Supply voltages.
\end{abstract}

\section{Keywords}

Full subtractor, MTCMOS, transistor gating, leakage current, power dissipation.

\section{INTRODUCTION}

In recent years, the usage of portable devices such as laptops, Smartphone, computers has been increased to great extent .The recognition and need of these portable electronic devices compels designers to aim for small silicon area, advanced speed, low power consumption and reliability. But these parameters are major concern in schematic design before their actual implementation in the layout. Subtractor is one of most significant and critical components of them. There are various possible logic styles compared to the basic CMOS logic style.

For any VLSI circuit, power dissipation ultimately contributes to cost and complexity of that circuit. So, area and power efficient design of logic gates is necessary in these portable devices. In digital circuits, arithmetic circuits play an important role. In the processor of portable devices, subtractor is one of the most critical components used in digital circuits. Thus we focus on area and power efficient design of subtractor to design small portable devices.

In the past, for any VLSI circuits main concern was the area, performance and reliability of the design. But nowadays as the demand for portable devices gained importance, the main concern is power consumption, cost and area comparable to reliability and speed considerations. Low power VLSI design can be classified into two major categories: Analysis and Optimization.

1) Analysis is related to accurate estimation of power or dissipation of energy during different design phase of circuits. Accuracy and efficiency differs in various techniques of analysis.
2) Optimization is the process of generating the best design, achieved the optimized goal without violating design specifications.

With rapid expanding market, demand for low power electronic products is booming. Due to increased device density, speed and complexity semiconductor industries present rigorous requirements to power distribution of digital chips.

\section{SUBTRACTOR}

A subtractor is one of the four basic binary operations, which performs the subtraction. Subtractors are not only applied on arithmetic calculations, but in other parts of processor. It operates on binary numbers and results in binary numbers. Depending upon the purpose of the application to be performed, inputs vary. For two inputs, half subtractor is used and if we have three input we apply full subtractor to get the outputs.

\subsection{Full Subtractor}

A Full subtractor is a combinational circuit that performs a subtraction between two binary bits and can borrow 1 from lower significant stage. Thus circuit has three inputs and two outputs. Let A, B and Borrow in (Bin) be three inputs and two outputs Borrow out (bout) and Difference (Diff).It can be design by two 2-input EXOR gate, two 2-input AND gate, two

1-input inverter and single 2-input OR gate. The gate level of Full Subtractor has been shown in Figure 1 and Truth table 1. Boolean expressions for the two output variables are obtained from karnaugh map.

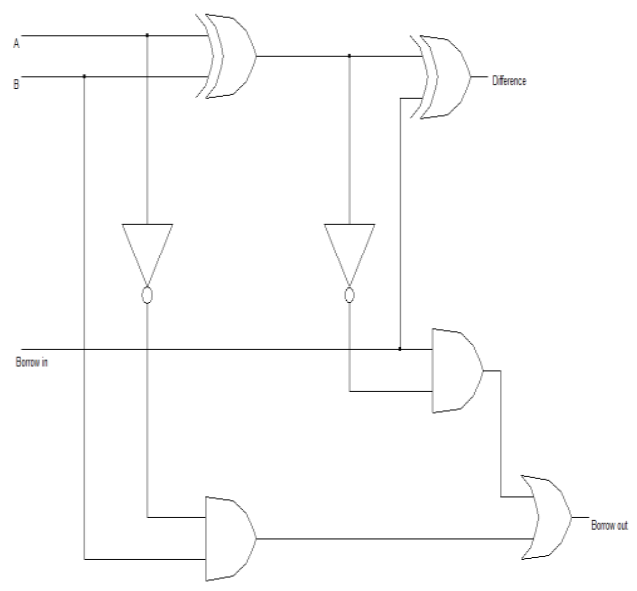

Figure 1. Gate-level Full Subtractor 
Table 1. Truth table of Full Subtractor

\begin{tabular}{|c|c|c|c|c|}
\hline A & B & $\begin{array}{c}\text { Borrow in } \\
\text { (Bin) }\end{array}$ & $\begin{array}{c}\text { Borrow out } \\
\text { (Bout) }\end{array}$ & $\begin{array}{c}\text { Difference } \\
\text { (Diff) }\end{array}$ \\
\hline 0 & 0 & 0 & 0 & 0 \\
\hline 0 & 0 & 1 & 1 & 1 \\
\hline 0 & 1 & 0 & 1 & 1 \\
\hline 0 & 1 & 1 & 1 & 0 \\
\hline 1 & 0 & 0 & 0 & 1 \\
\hline 1 & 0 & 1 & 0 & 0 \\
\hline 1 & 1 & 0 & 0 & 0 \\
\hline 1 & 1 & 1 & 1 & 1 \\
\hline
\end{tabular}

Boolean expressions are -

1. Difference $=\mathrm{A} \phi \mathrm{B} \phi \mathrm{C}$

$$
=\mathrm{ABC}+\mathrm{A}^{\prime} \mathrm{B}^{\prime} \mathrm{C}^{\prime}+\mathrm{A}^{\prime} \mathrm{BC} \mathrm{C}^{\prime}+\mathrm{AB}^{\prime} \mathrm{C}^{\prime}
$$

2. Borrow $=\mathrm{A}^{\prime} \mathrm{B}+\mathrm{A}^{\prime} \mathrm{C}+\mathrm{BC}$

$$
=A B C+A^{\prime} B^{\prime} C^{\prime}+A^{\prime} B
$$

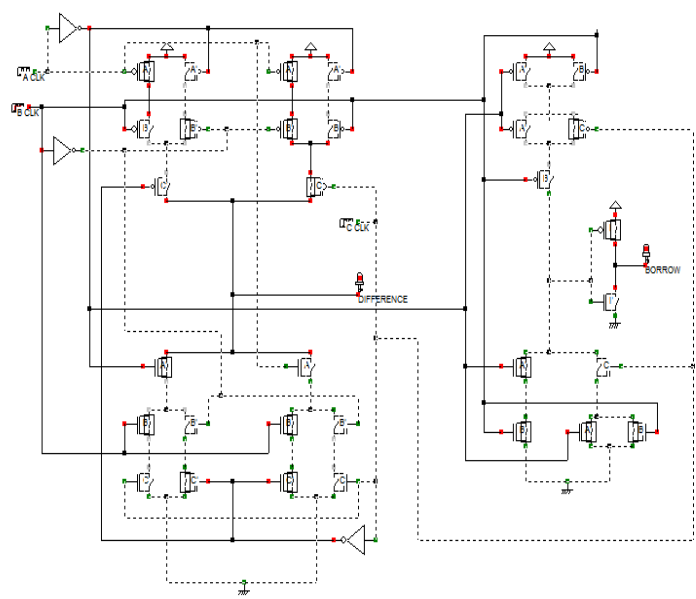

Figure 2. Transistor level design of conventional Full Subtractor

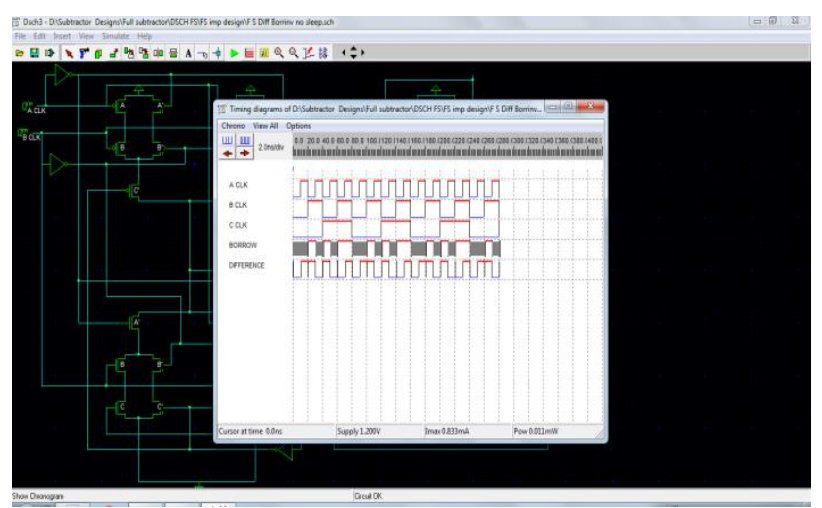

Figure 3. Timing simulation of conventional Full Subtractor in DSCH tool

\section{MTCMOS TECHNIQUE}

In this technique two sleep transistor PMOS and NMOS are inserted in between supply voltage and ground. A PMOS is implanted in between pull-up network and network output. A NMOS is inserted in between pull down network and ground. During standby mode both sleep transistor are turned off. To reduce the voltage in power supply, method requires reducing transistor threshold voltage to maintain noise margins and output. But this increases the sub threshold leakage current in $\mathrm{p}$ and $\mathrm{n}$ MOSFET's, increasing the overall power consumption. Thus transistor gating technique is implemented to reduce the power dissipation and leakage current. MTCMOS (Multi Threshold CMOS) technique has two main features:

1. Two operational modes, active and sleep mode to organize the power management.

2. Two dissimilar threshold voltages cutting off the low $\mathrm{V}_{\mathrm{t}}$ from power supply and high $\mathrm{V}_{\mathrm{t}}$ from ground circuit.

\subsection{Transistor Gating}

The proposed TRANSISTOR GATING technique uses two sleep transistor PMOS and NMOS embedded in the circuit. The PMOS sleep transistor (S) is added in between the pull-up network and network output and NMOS sleep transistor (S') is added between the pull down network and ground. This method is applied on Full Subtractor circuit. Figure 4 below describes the transistor gating.

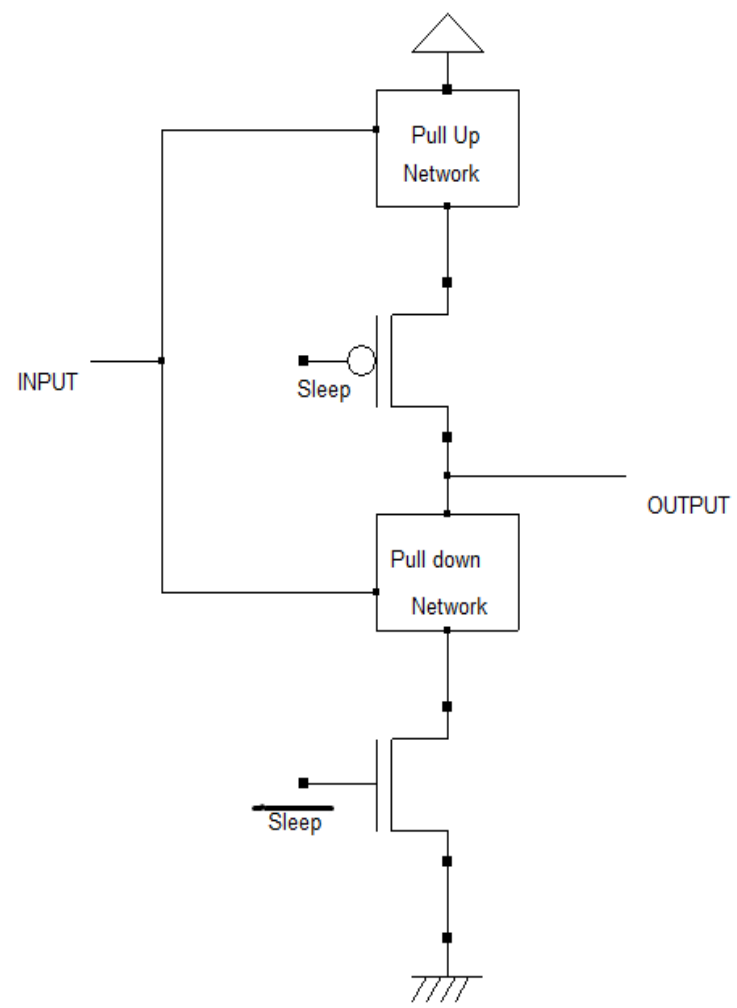

Figure 4. Transistor Gating Technique

\section{PARAMETER CALCULATIONS}

The performance assessment of full subtractor is established on area and power consumption, power delay, power dissipation and Power-Delay-Product. Area, speed and power consumption are the main issues in VLSI design which conflict with each other and act as constrain on the design of VLSI circuits .

On the basis of different logic styles, various designs of full subtractor are individually investigated, analyzed on these performance criteria. 


\subsection{Power Parameter calculation}

Due to lower power dissipation in Complementary MetalOxide Semiconductor (CMOS), it has advantage over other completing technologies like Transistor- Transistor Logic (TTL) and Emitter Coupled Logic (ECL). The various leakages - control techniques have been developed to attain the low- voltage, high-performance, low-leakage systems. Low threshold transistors are used to improve performance. High threshold are used to control leakage. Multiple Threshold CMOS (MTCMOS) isolates low threshold circuits from power and ground support using high threshold devices. Power dissipation is approximately proportional to the square of voltage supply. Thus lowering the supply voltage is the most competent way to achieve low power performance. In the following years, chip designers relied on scaling down the voltage supply to cut down the dynamic power dissipation, caused due to large number of transistors in chip. To maintain the switching speeds of high transistors we need to scale down the threshold voltage. But this causes the significant amount of leakage power dissipation even when the transistor is not switching.

The downscaling of device dimensions and drops off the supply voltage, which decrease the power consumption of single transistor. On the other hand, exponential increase of operating frequencies results in steady rise of the total power consumptions.

The main parameters that contribute to the total power dissipation are dynamic power, static power and short-circuit power. The expression can be stated as below-

$\mathrm{T}_{\text {total }}=\mathrm{P}_{\text {dynamic }}+\mathrm{P}_{\text {static }}+\mathrm{P}_{\text {short-circuit }}$

\section{(1) Dynamic Power Dissipation}

It attributes mainly in the power dissipation. Due to capacitive charging and discharging of the output wiring and when transistor switches state from $\mathrm{ON}$ to $\mathrm{OFF}$ and vice versa, causes the dynamic power dissipation. When the transition occurs from ' 0 ' to ' 1 ' and vice versa, both PMOS and NMOS transistors switched $\mathrm{ON}$ for short period of time. This results in short current flow from $\mathrm{V}_{\mathrm{dd}}$ to $\mathrm{V}_{\mathrm{ss}}$. For capacitive load, current is required to charge and discharge. Short circuit current is produced when there is no load capacitance. With the hike in capacitive load, charge and discharge current starts prevailing the main current.

$\mathrm{P}_{\text {dynamic }}=\mathrm{K} \cdot \mathrm{C} \cdot \mathrm{V}_{\mathrm{dd}}^{2} \cdot \mathrm{F}_{\mathrm{sw}}$

Where,

$$
\begin{aligned}
& \mathrm{K}=\text { Technology factor } \\
& \mathrm{C}=\text { Capacitance of switching nodes } \\
& \mathrm{V}_{\mathrm{dd}}=\text { Supply voltage } \\
& \mathrm{F}_{\mathrm{sw}}=\text { Effective switching frequency }
\end{aligned}
$$

\section{(2) Short Circuit Power Dissipation}

Short circuit power is part of dynamic power consumption, it relied on signal transition. It occurs due to rise time and fall time of signal. For short period of time PMOS and NMOS are $\mathrm{ON}$, so there will be a path from $\mathrm{V}_{\mathrm{dd}}$ to $\mathrm{V}_{\mathrm{ss}}$. Basically CMOS have minimal period of short circuit current flow but this period increases with supply voltage. Therefore it is factor of supply voltage and directly proportional to $\mathrm{V}_{\mathrm{dd}}$. With the reduction in $V_{d d}, t_{r}$ and $t_{f}$ parameters will increase.

$\mathrm{P}_{\mathrm{sc}}=\mathrm{V}_{\mathrm{dd}}\left[\left(\mathrm{I}_{\mathrm{pr}} \mathrm{t}_{\mathrm{r}}\right) / 2+\left(\mathrm{I}_{\mathrm{pf}} \mathrm{t}_{\mathrm{f}}\right) / 2\right] \mathrm{f}_{\mathrm{sw}}$

$\mathrm{P}_{\mathrm{sc}}=\mathrm{I}_{\mathrm{sc}} \cdot \mathrm{V}_{\mathrm{dd}} \cdot \mathrm{t}_{\mathrm{s}} \cdot \mathrm{f}_{\mathrm{sw}}$
Where,

$$
\begin{aligned}
& \mathrm{I}_{\mathrm{pr}}=\text { Current during the rise time } \\
& \mathrm{I}_{\mathrm{pf}}=\text { Current during the fall time } \\
& \mathrm{t}_{\mathrm{r}}=\text { Rise }- \text { time period } \\
& \mathrm{t}_{\mathrm{f}}=\text { Fall }- \text { time period } \\
& \mathrm{F}=\text { Switching frequency } \\
& \mathrm{I}_{\mathrm{sc}}=\text { Short circuit current } \\
& \mathrm{t}_{\mathrm{s}}=\text { Switching delay }
\end{aligned}
$$

\section{(3) Static Power Dissipation:}

The static power dissipation is the product of leakage current and supply voltage. The total static power dissipation $\mathrm{P}_{\mathrm{s}}$ is given by

$\mathrm{P}_{\mathrm{s}}=\sum_{l}^{n}$ Leakage current $\times$ Supply voltage

Where, $n=$ Number of devices

\subsection{Leakage Current Calculation}

The leakage current equation can be represent as

$\mathrm{i}_{\mathrm{o}}=\mathrm{i}_{\mathrm{s}}\left(e^{q V / k T}-1\right)$

Where,

$\mathrm{i}_{\mathrm{s}}=$ Reverse saturation current

$\mathrm{V}=$ voltage of diode

$\mathrm{q}=$ Electronic charge

$\mathrm{k}=$ Boltzmann constant

$\mathrm{T}=$ Temperature

Sub threshold or weak inversion conduction current between source and drain in a MOS transistor occurs when gate voltage is below the transistor threshold voltage. The Sub threshold or weak inversion current $\mathrm{I}_{\mathrm{ds}}$ can be written as-

$$
\begin{aligned}
& \mathrm{I}_{\mathrm{ds}} \quad=\mathrm{I}_{\mathrm{dso}} e^{(\mathrm{Vgs}-\mathrm{Vt} / \mathrm{nVT})}\left[1-e^{V d s / V T}\right] \\
& \mathrm{I}_{\mathrm{dso}}=\mu_{\mathrm{eff}} \mathrm{c}_{\mathrm{ox}}(\mathrm{W} / \mathrm{L}) \mathrm{V}_{\mathrm{T}}{ }^{2}
\end{aligned}
$$

Where,

$$
\begin{array}{ll}
\mu_{\mathrm{eff}} & =\text { Charge carrier mobility } \\
\mathrm{c}_{\mathrm{ox}} & =\text { Gate capacitance } / \text { unit area } \\
\mathrm{W} / \mathrm{L} & =\text { Width to length ratio of channel } \\
\mathrm{V}_{\mathrm{t}} & =\text { Threshold voltage } \\
\mathrm{V}_{\mathrm{T}} & =\text { Thermal voltage } \\
\mathrm{n} & =\text { Sub- threshold swing coefficient } \\
\mathrm{V}_{\mathrm{gs}} & =\text { Gate to source voltage } \\
\mathrm{V}_{\mathrm{ds}} & =\text { Drain to source voltage }
\end{array}
$$

\section{PREVIOUS WORK DONE}

The previous work done to design the Full Subtractor with different techniques and different structure is surveyed and analyzed below:

[1] In 2012, Milind Gautam, Shyam Akashe proposed Transistor Gating technique implemented in Full subtractor circuit. In this paper, low-power design techniques proposed to minimize the standby leakage power in nanoscale CMOS. The tool used for schematic simulation is CADENCE VIRTUOSO in $45 \mathrm{~nm}$ technology. This technique results in 
reduction in leakage current by $17.58 \%$ and $24.38 \%$ reduction in leakage power.

[2] In 2015, Dr.PR Reddy, Dr. KV Ramanaiah, MM Basha presented different design circuit on full Subtractor implanting the MTCMOS technique. The tool used is Microwind $3 / \mathrm{DSCH}$ in $65 \mathrm{~nm}$ technology. The BSIM 4 parameter analyzer is used to analyze the proposed circuit. The proposed design of 14 transistor 1-bit Full subtractor at $1.0 \mathrm{v}$ results in power consumption of $1.896 \mu \mathrm{w}, \mathrm{I}_{\mathrm{ddmax}}$ is $0.197 \mathrm{~mA}$, area as 240 $\mu \mathrm{m}^{2}$ and delay power calculated is $131 \mathrm{ps}$.

[3] In 2013, a paper presented by M. Gautam and S. Akashe on a full subtractor using MTCMOS technique to minimize the active leakage power. Simulation result is done at 0.7 volt designing on CADENCE VIRTUOSO tool in 45 nanometer technology. The proposed design results in reduction of leakage current by $15.63 \%$ and power is $95 \%$ compare to conventional full subtractor circuit.

\section{PROPOSED METHODOLOGY}

The proposed Full subtractor design is shown in Figure 5. In this sleep transistors are implemented with Sleep Clock input. A sleep transistor is referred as either PMOS or NMOS high $\mathrm{V}_{\mathrm{th}}$ transistor that connects permanent power supply to circuit power supply commonly called as "Virtual power supply".

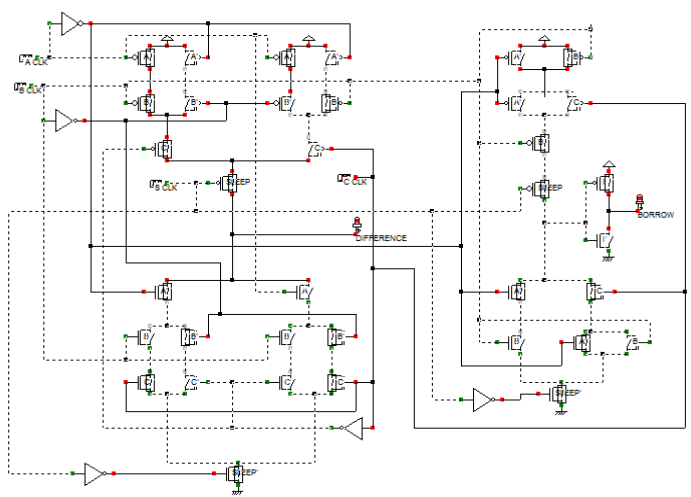

Figure 5. Proposed Full Subtractor Design

\section{LAYOUT ANALYSIS}

Timing simulation of proposed full Subtractor shows in figure 6. Simulation has been done on DSCH designing tool to get the timing waveform. The timing waveform is generated for the two outputs Difference and Borrow to the truth table.

In DSCH designing tool schematic diagram has been firstly designed and validated at logic level on DSCH designing tool. VERILOG file is generated by DSCH 3.1 tool which is compiled by MICROWIND to construct the corresponding layout with exact desired design rules. It has advantage approach to avoid any design rule error.

Table 2. Comparison Table

\begin{tabular}{|c|l|l|l|}
\hline Parameter & $\begin{array}{l}\text { Base } \\
\text { Paper }\end{array}$ & \multicolumn{2}{|c|}{ Proposed Paper } \\
\cline { 2 - 4 } & $\begin{array}{l}\text { Proposed } \\
\text { Full } \\
\text { Subtractor }\end{array}$ & $\begin{array}{l}\text { Conventional } \\
\text { Full } \\
\text { Subtractor }\end{array}$ & $\begin{array}{l}\text { Proposed } \\
\text { Full } \\
\text { Subtractor }\end{array}$ \\
\hline $\begin{array}{c}\text { Power } \\
\text { Dissipation }\end{array}$ & $4.081 \mathrm{~mW}$ & $2.391 \mathrm{~mW}$ & $0.341 \mathrm{~mW}$ \\
\hline
\end{tabular}

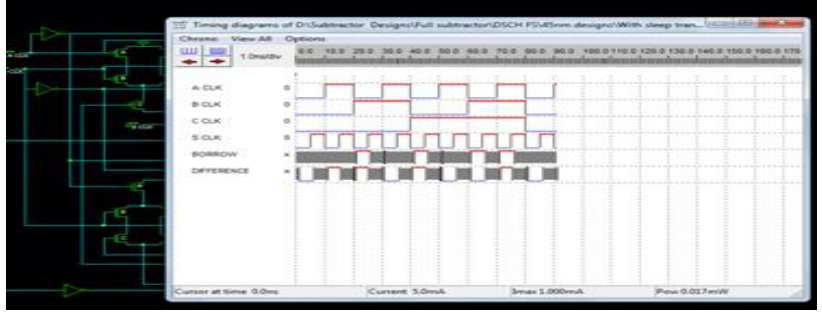

Figure 6. Timing simulation of proposed Full Subtractor in DSCH tool

\section{SIMULATION RESULT}

The evaluation of proposed Full Subtractor design has been on $45 \mathrm{~nm}$. The MICROWIND 3.1 has been used for simulation in terms of power and current with respect to variation in voltage. The output wave forms of the conventional and proposed full subtractor are shown below in Figure 7 and Figure 8 respectively. The W/L ratio has been varied during simulation to obtain various graph such as $I_{d}$ vs $V_{d}$, threshold voltage.

Table 3. Details of Specifications Used

\begin{tabular}{|l|l|l|}
\hline S. No & \multicolumn{1}{|c|}{ Specifications } & \multicolumn{1}{|c|}{ Details } \\
\hline 1. & Software & Microwind 3.1/DSCH 3.1 \\
\hline 2. & Simulation Level & BSIM (advanced) \\
\hline 3. & Simulation Technology & $45 \mathrm{~nm}$ \\
\hline 4. & Supply Voltage & 0.7 Volts \\
\hline
\end{tabular}

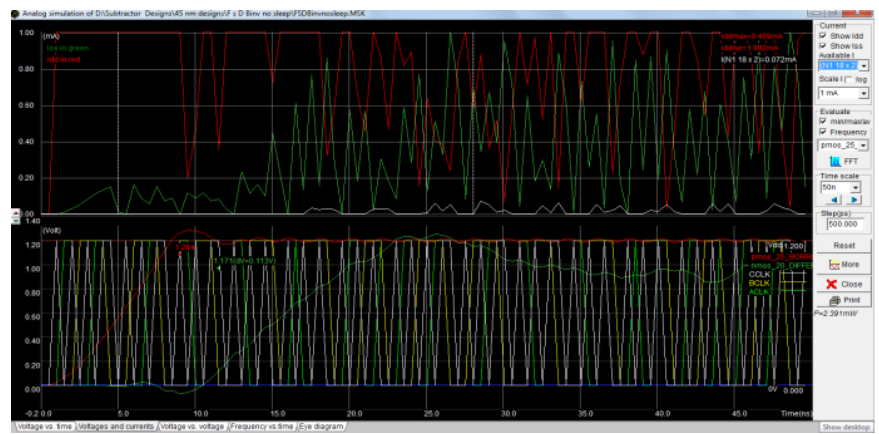

Figure 7. Voltage and current graph of conventional Full Subtractor

The conventional Full Subtractor has power calculated as $2.391 \mathrm{~mW}$ and proposed Full Subtractor power is reduced to $0.341 \mathrm{~mW}$. The $\mathrm{I}_{\mathrm{dd}(\max )}$ and $\mathrm{I}_{\mathrm{dd}(\text { avg) }}$ for Conventional circuit is $9.409 \mathrm{~mA}$ and $1.992 \mathrm{~mA}$ respectively, whereas for proposed design $\mathrm{I}_{\mathrm{dd}(\max )}$ and $\mathrm{I}_{\mathrm{dd}(\mathrm{avg})}$ is $2.420 \mathrm{~mA}$ and $0.487 \mathrm{~mA}$ respectively.

Table 4. Simulation Result Analysis

\begin{tabular}{|c|c|c|c|}
\hline S. No & Parameter & $\begin{array}{c}\text { Conventional } \\
\text { Full } \\
\text { Subtractor }\end{array}$ & $\begin{array}{c}\text { Proposed } \\
\text { Full } \\
\text { Subtractor }\end{array}$ \\
\hline 1. & Power Dissipation & $2.391 \mathrm{~mW}$ & $0.341 \mathrm{~mW}$ \\
\hline 2. & $\mathrm{I}_{\mathrm{dd}} \max$ & $9.409 \mathrm{~mA}$ & $2.420 \mathrm{~mA}$ \\
\hline 3. & $\mathrm{I}_{\mathrm{dd}}$ avg & $1.992 \mathrm{~mA}$ & $0.487 \mathrm{~mA}$ \\
\hline 4. & Area & $164.7 \mu \mathrm{m}^{2}$ & $205.4 \mu \mathrm{m}^{2}$ \\
\hline
\end{tabular}




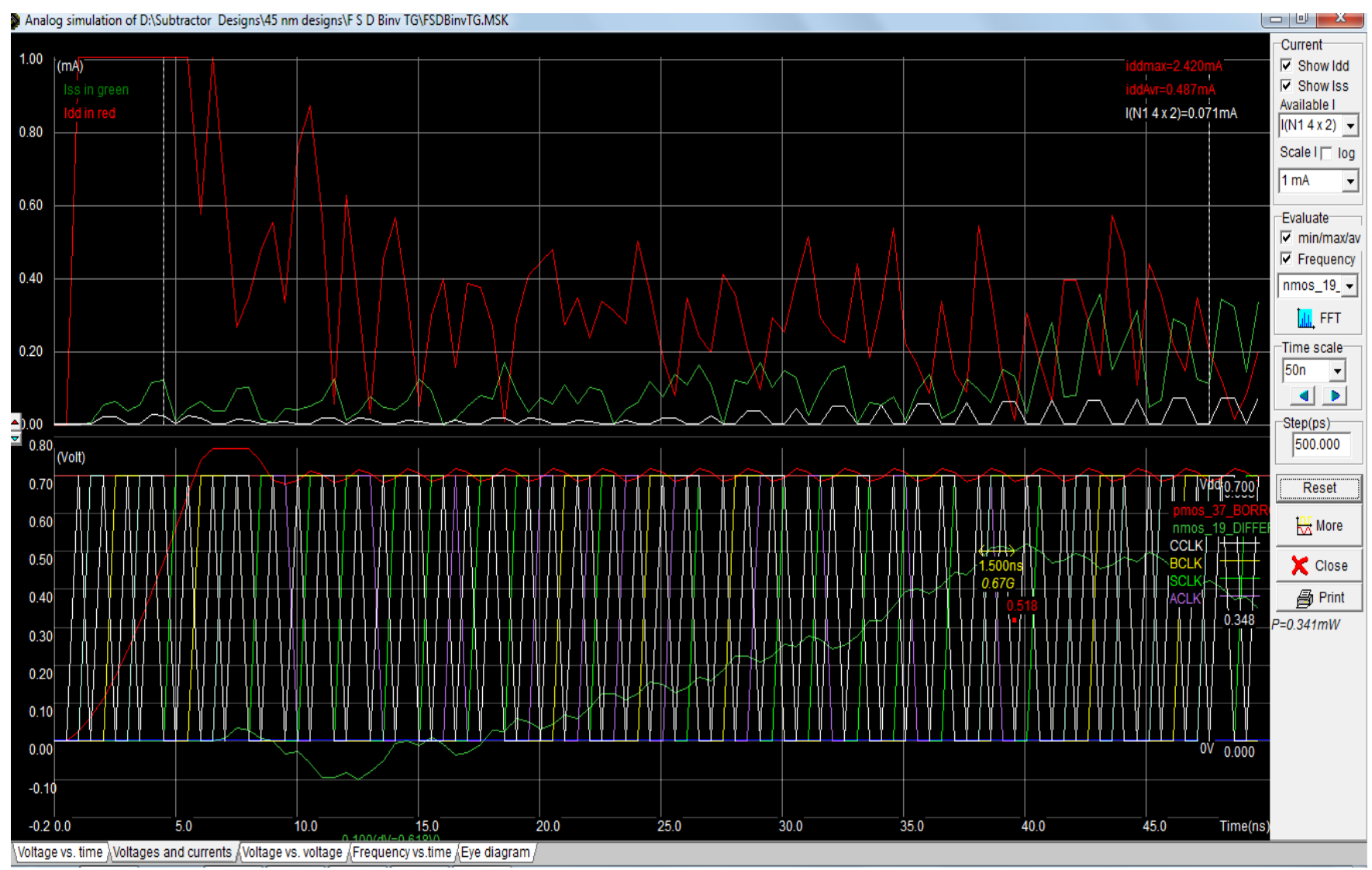

Figure 8. Voltage and Current graph of proposed Full Subtractor circuit design

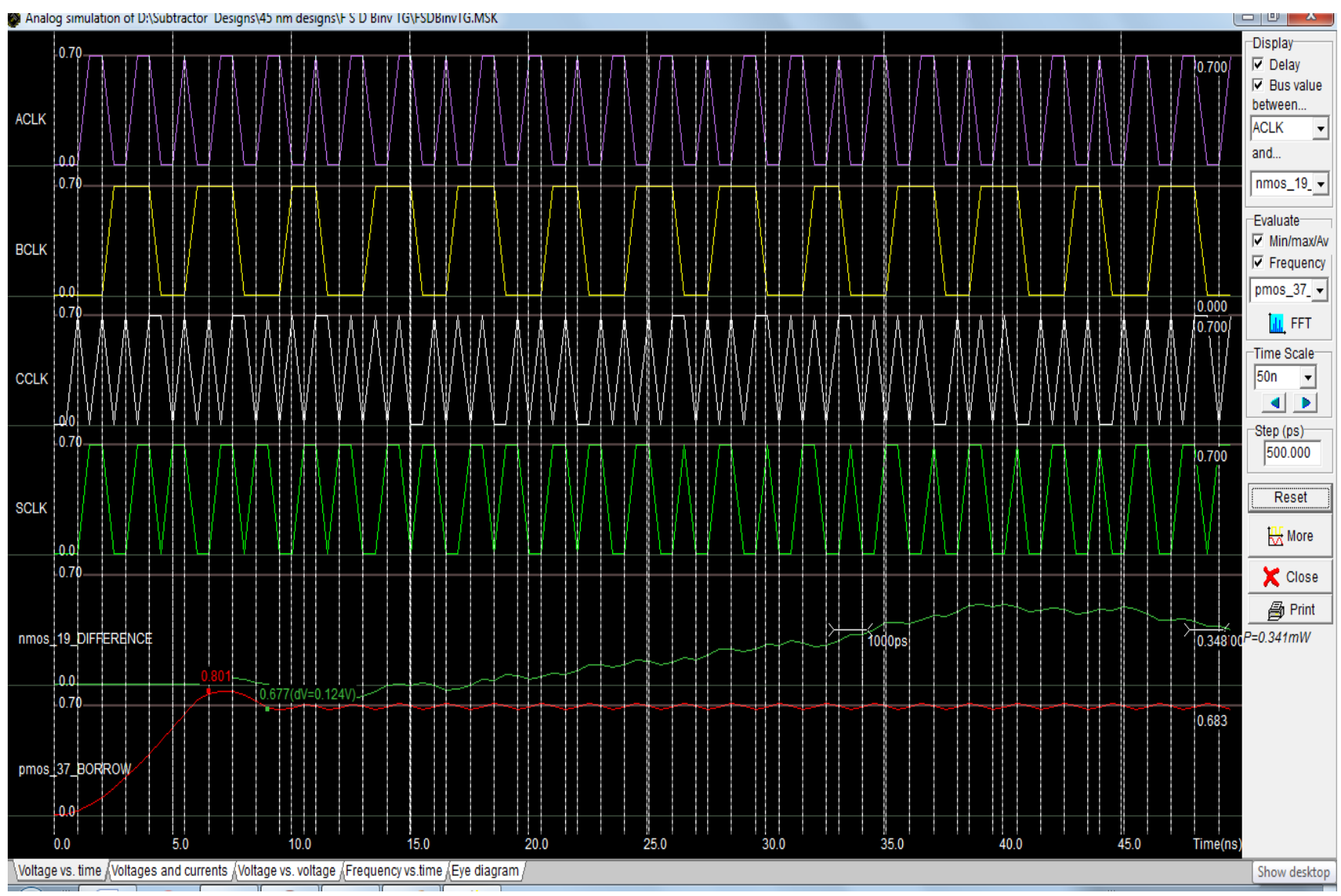

Figure 9. Voltage versus time graph of proposed Full Subtractor circuit design 


\section{CONCLUSION}

In this paper, reduction in average power which leads to reduction in leakage current and dynamic power dissipation is analyzed for conventional and modified Full Subtractor circuits using Microwind / DSCH tool in 45nm technology. Proposed Full Subtractor circuits in MTCMOS mode is analyzed in terms of power, current, area. The proposed design power consumption calculated as $0.341 \mathrm{~mW}$, maximum current equal to $2.420 \mathrm{~mA}$ and average current as $0.487 \mathrm{~mA}$ at 0.7 Supply voltages. The simulation level is BSIM advanced level. The completion of this main task was satisfactory since the theoretical expectations matched our experimental results.

\section{ACKNOWLEDGEMENT}

Author would like to thank NIIST Bhopal College for providing Microwind / DSCH software to carry out thesis work and their valuable guidance from time to time.

\section{REFERENCES}

[1] Gautam M., Akashe S., "Transistor gating: reduction of leakage current and power in full subtractor circuit." Advance Computing Conference (IACC), 2013,pp 15141517.

[2] Basha MM., Dr.Ramanaiah KV, Dr.Reddy PR, "Novel energy efficient 1-bit full subtractor at $65 \mathrm{~nm}$ technology" Electrical, Electronics, Signals, Communication and Optimization (EESCO), 2015.

[3] Gautam M., Akashe S., "Reduction of leakage current and power in full subtractor using MTCMOS technique"
Computer Communication and Informatics (ICCCI), 2013.

[4] Krishna S., Raghu MC and Faris S., "An efficient design of full Subtractor cell and its application in ripple borrow subtractor" International Journal of Advanced Research in Electronics and Communication Engineering (IJARECE) Volume 4, Issue 5, May 2015, pp 14731476.

[5] Saroja MD, Naik MR, "Reduction of leakage current and power in full subtractor using MTCMOS technique" International Journal of Review in Electronics and Communication Engineering IJRECE (2014) Vol2, Issue 4, August 2014

[6] Rawat N., Jain R. "Power reduction approach in combinational circuit (Half and full subtractor)" International Journal of Science and Research (IJSR) Volume 3, Issue 7, July 2014.

[7] Sandana K., Sujitha K., "Static power dissipation reduction on full subtractor using MTCMOS" International Journal of Engineering \& Science Research IJESR, July 2014, Vol-4, Issue-7,425-430.

[8] Sood T., Mehra R., "Design a Low Power HalfSubtractor Using $.90 \mu \mathrm{m}$ CMOS Technology" IOSR Journal of VLSI and Signal Processing (IOSR-JVSP) Volume 2, Issue 3 (May. - Jun. 2013), PP 51-56. 